\title{
Management Strategies of Nipple Discharge
}

\author{
OSAMA ABD ALLAH, M.D. \\ The Department of General Surgery, Shibin El-Kom Teaching Hospital
}

\begin{abstract}
Background: Nipple discharge (ND) is defined as a fluid that flows or is expressed from the mammary ducts. Nipple discharge is classified as benign or pathologic on the basis of its clinical characteristics. Unilateral spontaneous bloody or clear nipple discharge from a single duct may be the first sign of breast carcinoma needing further evaluation.
\end{abstract}

Aim of Study: The aim of this study is to assess management strategies for patients with nipple discharge (ND).

Patients and Methods: This study was carried out on 50 female patients who presented with nipple discharge in the out patient clinics of Shebin El-Kom Teaching Hospital.

Lactating females were excluded from the study. Patients were followed up for a minimum of 3 months and a maximum of 18 months on monthly basis.

Results: The success rate of conservative management for benign ND was $88 \%$. The discharge immediately stopped in patients managed by microdochectomy but hematoma developed in only one case that got resolved spontaneously. The discharge stopped in all patients managed by major duct excision, Discharge stopped immediately, but recurrence occured in two patients with purulent discharge. They need revision surgery for further debridement. In cases presented with a lump and FNAC showed malignant cells $16 \%$ (4 cases) they managed by modified radical mastectomy, the wound disrupted in one case, it occurs at the mammary fold and managed by secondary sutures later on.

Conclusion: This study reveals the accuracy of clinical examination, sonomammography \& FNAC in evaluating breast lump especially when applied together.

Key Words: Discharge - Aspiration cytology - Fine-needle - Carcinoma - Clinical examination - Ultrasonography-Mammography.

\section{Introduction}

NIPPLE discharge is the third most common breast complaint, for which women seek medical attention after lumps and breast pain. A woman's breasts have some degree of fluid secretion activity throughout most of the adult life. The difference

Correspondence to: Dr. Osama Abd Allah, The Department of General Surgery, Shibin El-Kom Teaching Hospital between lactating and non-lactating breasts is mainly in the degree or amount of secretion and to a smaller degree in the chemical composition of the fluid [1].

The first step in the evaluation of a nipple discharge is to determine whether the discharge is pathologic or physiologic [2]. Based on the findings of the history and physical examination [3].

Nipple discharge is most often due to a benign process. This common breast problem has been reported in 10 to 15 percent of women with benign breast disease and in 2.5 to 3 percent of women with breast cancer. However, using an aspiration pump, secretions can be obtained from 50 to 80 percent of women without known breast disease [4].

Triple assessment is a simple, safe, cost effective and can be applied for every patient before definitive treatment can be started [5].

\section{Patients and Methods}

This prospective study included 50 patients presented at Shebin El-Kom Teaching Hospital, during the period of March 2018 till Septemper 2019. Lactating females were excluded from the study. Patients were followed-up for a minimum of 3 months and a maximum of 18 months on monthly basis regarding examination of the discharge (increase, decrease, localized to single duct, change in colour, with periodic testing for occult blood), examination of both breasts (size, appearance of any breast lump or any change in the consistency of already present lump) and examination of the axillary lymph nodes. Every patient was subjected to:

- Full history taking.

- Examination: General \& Local examination. 
- Investigations: Laboratory, Hormonal assay, Discharge examination (cytology \& Benzidine test for all cases, Culture and sensitivity), Imaging studies (bilateral mammosonography, Galactography) and FNAC.

\section{Results}

This prospective study included 50 patients presented with nipple discharge, the age was ranged between 18 years and 70 years with a mean age of 40.82. Whereas the highest incidence $(28 \%)$ of breast lump occurred in the age group 25-35 years (Table 1).

The duration of the discharge ranged from 1 month to 7 years with a mean duration of 10.9 months. In thirty-three patients (66\%) the discharge was unilateral and in 17 patients $(34 \%)$ the discharge was bilateral. In eighteen patients (36\%) the discharge was uniorificial and in thirty-two (64\%) patients the discharge was multiorificial. In twelve patients (24\%) the discharge was spontaneous and in thirty-eight patients (76\%) the discharge occurred by areolar and peri-areolar squeezing. In eighteen patients $(36 \%)$ the discharge was uniorificial and in thirty-two (64\%) patients the discharge was multiorificial. In eight cases $(16 \%)$ the discharge was persistent and in forty two cases (84\%) the discharge was intermittent (Table 2).

Twenty one $(42 \%)$ patients presented with serous discharge. Eleven (22\%) patients presented with serosanguineous discharge. Eight (16\%) patients presented with bloody discharge. Four (8\%) patients presented with purulent discharge.Four (8\%) patients presented with creamy discharge. Two (4\%) patients presented with milky discharge.

- Twenty three (46\%) patients were complaining of mastalgia.

- Alump was found in twenty five cases (50\%); six cases of them were associated with palpable axillary lymph nodes. These lumps proved by histopathological examination to be fibrocystic in twelve cases (48\%), fibrocystic with ductectrasia in four cases $(16 \%)$, fibrocystic with duct papillomatosis tow cases (8\%), ductectesia in three cases $(12 \%)$ and invasive duct carcinoma in four cases $(16 \%)$. Nipple retraction was found in three cases (6\%), two cases proved to be invasive duct carcinoma and one case with congenital nipple retraction proved to be ductectesia. Four cases (8\%) presented after previous drainage of breast abscesses and they had purulent discharge. None of the patients presented with breast or chest trauma. Skin changes in the form of dimpling and peau d'orange were present in three cases proved to be invasive duct carcinoma.
In four cases with purulent discharge, culture and sensitivity was done. In three cases the causative organism was staphylococci and treated by amoxycillin clavulunic acid combination. In the remaining cases streptococci was the causative organism that treated by flocloxacilline.

Benzidine test was done for all cases. The test was positive in thirteen cases (26\%), eight cases (62\%) with bloody discharge and five cases (38\%) with serosanguineous discharge. Two cases $(25 \%)$ out of eight cases with bloody discharge were diagnosed as duct carcinoma, three cases (37.5\%) were diagnosed as duct papilloma. In the other five cases with serosanguineous discharge, two cases $(40 \%)$ were diagnosed as duct carcinoma. In two cases (4\%) with milky discharge suspected to be galactorrhea, serum prolactin was done and it was above its normal levels. In four cases (8\%) the cytological examination was positive for malignant cells. The exfoliative cytological examination for nipple discharge was done for all cases. Benign lesions were found in thirtysix (72\%) cases, duct papilloma in three cases (6\%), and inflammatory cells only (inconclusive) in seven cases (14\%).

By mammosonography no patient was in category 0,6 pateints were in category $1(12 \%), 30$ patients in category $2(60 \%), 8$ patients in category $3(16 \%), 4$ patients in category $4(8 \%)$, and 2 patients in category 5 (4\%). (Table 3) (Fig. 1).

Ductography was done in eighteen cases (36\%) presented with uniorificial nipple discharge (six cases associated with benign lump and twelve cases without lump). In five cases (28\%) the ductogram showed duct dilatation, in four cases $(22 \%)$ it showed a single filling defect, in three cases $(17 \%)$ it showed multiple filling defects, in three cases $(17 \%)$ it showed paraductal cysts, and it showed normal ductogram in three cases $(17 \%)$.

FNAC was done in twenty five cases presented with nipple discharge associated with lump. Twenty one cases (84\%) showed benign lesions while in four cases $(16 \%)$ it showed malignant cells.

Table (1): The age incidence among patients with nipple discharge.

\begin{tabular}{lcl}
\hline Age group & No. of cases & $\%$ \\
\hline From 18 to $<25$ & 4 & 8 \\
From 25 to $<35$ & 14 & 28 \\
From 35 to $<45$ & 12 & 24 \\
From 45 to $<55$ & 12 & 24 \\
From 55 to $<65$ & 7 & 14 \\
From 65 to $<75$ & 1 & 2 \\
\hline Total & 50 & 100 \\
\hline
\end{tabular}


Table (2): Characteristics of the discharge.

Table (3): Results of mammosonography.

\begin{tabular}{|c|c|c|c|c|c|}
\hline Character of discharge & No. of cases & $\%$ & BI-RADS & No. of patients & $\%$ \\
\hline Unilateral & 33 & 66 & Category 0 & 0 & 0 \\
\hline Bilateral & 17 & 34 & Category 1 & 6 & 12 \\
\hline Spontaneous & 12 & 24 & Category 2 & 30 & 60 \\
\hline On Squeezing & $\begin{array}{l}38 \\
18\end{array}$ & $\begin{array}{l}76 \\
36\end{array}$ & Category 3 & 8 & \\
\hline $\begin{array}{l}\text { Uniorificial } \\
\text { Multiorificial }\end{array}$ & $\begin{array}{l}18 \\
32\end{array}$ & $\begin{array}{l}36 \\
64\end{array}$ & Category 3 & 8 & 16 \\
\hline Persistent & 8 & 16 & Category 4 & 4 & 8 \\
\hline Intermittent & 42 & 84 & Category 5 & 2 & 4 \\
\hline
\end{tabular}
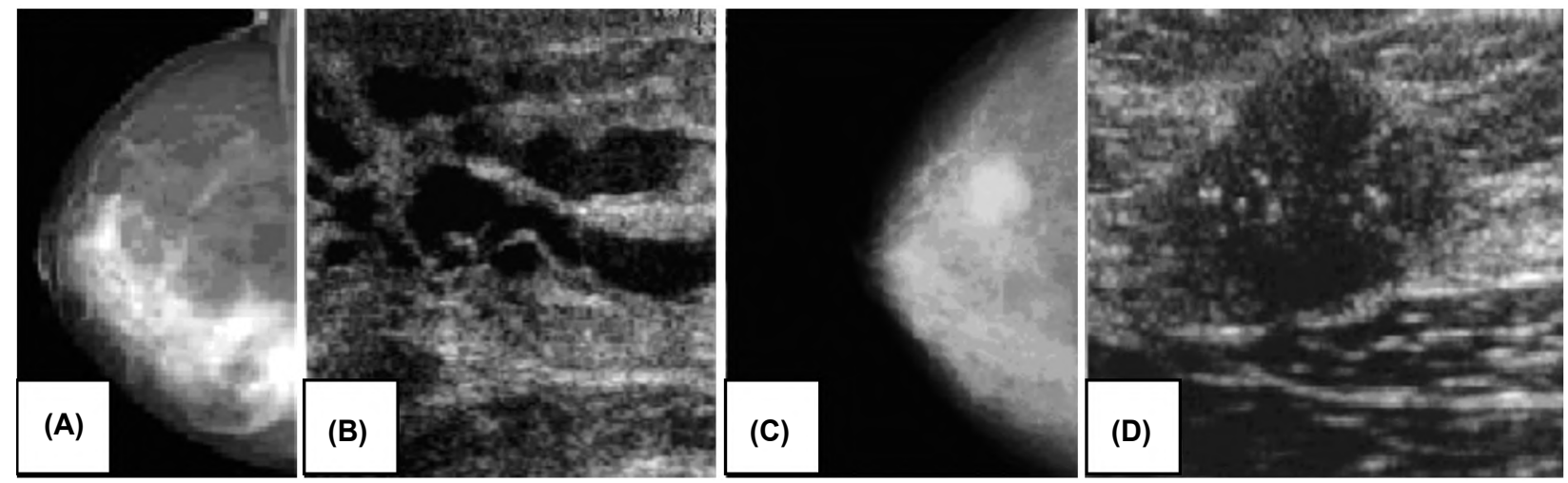

Fig. (1): (A\&B): Mammosonography: Ductectasia, BI-RADS (2). (C\&D) Mammosonography: Malignant mass with microcalcifications, BI-RADS (4).

\section{Discussion}

Breast lesions are commonly encountered lesions in surgical pathology. With increasing incidence of cancer breast, high level of preoperative diagnostic accuracy has become highly imperative. The highest level of preoperative diagnostic accuracy of breast lesions can be achieved using a triple approach. This concept combines the results of imaging, clinical examination and FNAC [4]

This study (Table 1) included 50 female patients with nipple discharge; the age incidence in this study ranged between 18 years and 70 years with a mean age of 40.82 years. Whereas the highest incidence (28\%) of nipple discharge occurred in the age group (25-35) years. This finding correlates with the results of [6] in their study on 500 female patients presented with nipple discharge in 20month period from January 2012 to September 2013 , the age of patients presented with nipple discharge ranged from 15 years to 60 years with a mean age of $39.6 \pm 11.8$ years. Whereas, the highest incidence $(29.8 \%)$ of nipple discharge occurred in the age group 40-<50 years [7]; in their retrospective study assessed data from the records of 13,443 patients who were examined and treated by these physicians between 1 January 1960 and 31 December 2000, ND was the presenting symptom in 603 (4.5\%) of the cases. Two hundred and eighty-seven
(48\%) of the 603 patients showed spontaneous nipple discharge (SND group) and the other 316 (52\%) showed provoked nipple discharge (PND group). The mean age in the spontaneous ND group was 44 years (range 12-75 years), and that in the provoked ND group was 38 years (range 16-70 years).(8) in their study during a period of 20 years and 8 months (January 1983-August 2003) 1530 patients were recorded; the age range between 1883 years in patients presented with the complaint of ND.

In the present study the duration of discharge ranges from 1 month to 7 years with a mean duration of 10.9 months. In thirty-three patients the discharge was unilateral and in 17 patients the discharge was bilateral. In twelve patients (24\%) the discharge was spontaneous and in thirty eight patients $(76 \%)$ the discharge occurred on areolar and periareolar squeezing. In eighteen patients $(18 \%)$ the discharge was uniorificial and in thirtytow $(64 \%)$ patients the discharge was multiorificial. In eight cases $(16 \%)$ the discharge was persistent and in forty two cases ( $84 \%$ ) the discharge was intermittent [5] had studied retrospectively 416 patients presenting with a chief complaint of ND from 1995 to 2005 . They found the duration of the discharge ranges from 1 week to 520 weeks with a mean duration of 260.5 weeks. The discharge was unilateral in 379 patients $(91 \%)$, and bilateral 
in 37 patients (8\%). In 323 patients $(78 \%)$ the discharge was spontaneous and in $93(22 \%)$ the discharge occurred on areolar and periareolar squeezing. In 216 patients (52\%) the discharge was uniorificial and $200(48 \%)$ patients the discharge was multiorificial. In 292 cases (70\%) the discharge was persistent and in 124 cases (30\%) the discharge was intermittent. This discrepancy may be due to the difference in number of the studied cases.

In the present study (Table 3), twenty one (42\%) patients presented with serous discharge, eleven (22\%) patients presented with serosanguineous discharge, eight (16\%) patients presented with bloody discharge, four ( $8 \%$ ) patients presented with purulent discharge, four $(8 \%)$ patients presented with creamy discharge, and two (4\%) patients presented with milky discharge [10]. Retrospectively analyzed all patients presenting with nipple discharge as their primary symptom to the symptomatic breast unit at a tertiary referral center over a 30-month period (No. 313). The discharge was bloody in $44 \%(137 / 313)$ of cases, serous in $42 \%(130 / 313)$ of cases, milky in 9\% (27/313) of cases and purulent in 6\% (19/313) of cases. While [11] had observed retrospectively in a study of 116 women who underwent ductal excision at the women's hospital of the University of Rostock, Germany, from January 1995 to December 2002 were that, twenty-six (22\%) patients presented with serous discharge, twelve $(10 \%)$ patients presented with brown discharge, ninety one (77\%) patients presented with sanguineous discharge, two (1\%) patients presented with green discharge, nine (7\%) patients presented with unknown colour discharge, and seven $(5 \%)$ patients presented with milky discharge.

In the present study we found Twenty three (46\%) patients were complaining of mastalgia. Breast lump was found in twenty five cases (50\%); six cases of them were associated with axillary lymph nodes. Nipple retraction was found in three cases. Skin changes in the form of dimpling and peau d"orange were present in three cases [12], in their study of 2,879 patients they found that 1,141 patients $(39.6 \%)$ complaining of pain, 1,663 patients $(57.8 \%)$ associated with breast lump, 1,173 patients $(40.7 \%)$ presented with breast mass.

In this study exfoliative cytological examination for nipple discharge was done for all cases. In this study the sensitivity of exfoliative cytology in diagnosing malignancy was $80 \%$, and the specificity $100 \%$. The positive predictive value for malignancy was $100 \%$, and the negative predictive value was $97.83 \%$. These findings agree with the results of the study performed by [13], on 466 case specimens from 395 patients from 1995-2002 presented with nipple discharge. Of the 395 patients, 98 had abnormal cytologic findings (27 cases with intraductal papilloma of which 24 cases with atypia, 9 cases with moderate epithelial hyperplasia, 3 cases with ductectasia, and 18 cases with duct carcinoma) The positive predictive value for cytology was $92 \%$ and the negative predictive value was $94 \%$. In 1 case review of 225 patients with abnormal nipple secretions [14]

Suggested that nipple cytology is a highly specific but relatively insensitive method for detecting malignancy (specificity: 100\%, sensitivity: $60 \%$ ). In a similar study, [15] compared the cytology of clear or sanguinous nipple discharge in 37 patients with subsequent histology and reported a sensitivity and specificity of $11.1 \%$ and $96.3 \%$, respectively. While in a study done by (16) and aimed to evaluate the diagnostic value of nipple discharge (ND) cytology and galactography: Ninety -four patients submitted to duct excision, representing a total of 98 duct excisions, were retrospectively analyzed from January 1997 to May 2007. Cytology had a sensibility and specificity in detecting duct pathology of, respectively, $40 \%$ and $61.3 \%$, a positive predictive value (PPV) of $53.8 \%$ and a negative predictive value (NPV) of $47.5 \%$.

In this study, all cases were subjected to bilateral mammosonography. Compared with the histopathological examination the mammogram with complementary US have sensitivity in diagnosing breast carcinoma of $80 \%$, the specificity was of $97.78 \%$, the positive predictive value (PPV) was $80 \%$ and a negative predictive value (NPV) of $97.78 \%$. In six cases with palpable axillary lymph nodes, the mammogram \& US showed axillary lymphadenopathy. These results are comparable with the results of [17]; who had studied 320 cases with nipple discharge, all cases were subjected to mammography, 20 cases $(6.25 \%)$ showed normal mammography, while 300 cases (93.75\%) showed abnormal mammogram. From these 300 cases, 160 cases (53\%) showed picture of fibrocystic disease, 40 cases $(13 \%)$ of ductectasia, 70 cases $(24 \%)$ of fibrocystic disease with ductectasia and 30 cases $(10 \%)$ showed malignant features. These results are contrary to [18], in their study of 1708 patients that presented with nipple discharge from 2004 to 2006. 98 cases undergo mammogram, with sensitivity of $38 \%$, specificity of $74 \%$, a positive predictive value (PPV) of $12 \%$ and a negative predictive value (NPV) of $93 \%$. These results are similar to results of the study done by [19] on 2185 patients 
at their symptomatic breast clinic between January 2000 and August 2003. In all, 999 of these patients had both mammogram and ultrasound examinations performed. The overall sensitivity of ultrasound based on final pathological outcome was $80.8 \%$, the Specificity was $99.1 \%$. However [20] who reviewed and analyzed the complete medical records of all patients who were evaluated at The University of Texas MD Anderson Cancer Center for a chief complaint of nipple discharge between August 1993 and September 2000 and found that the sensitivity of ultrasound was $80 \%$, the specificity was of $61.2 \%$, the positive predictive value (PPV) was $38.7 \%$ and a negative predictive value (NPV) of $90.9 \%$.

In the present study, ductography was done in eighteen cases $(36 \%)$. In fifteen cases the ductogram showed abnormal picture in the form of duct dilatation, single filling defect, multiple filling defects, paraductal cysts, and it showed normal ductogram in three cases (17\%) [21]. Reported abnormalities in 776 (97.9\%) out of 792 galactography. The abnormalities was duct dilatation in 31 (4\%) cases, singular filling defect in $270(45 \%)$ cases, multiple filling defect in $436(56 \%)$ cases, and suspected carcinoma in $39(5 \%)$ cases [20] Found that, of the 84 ductograms obtained in the clinically pathologic discharge group, only 4 revealed normal findings. The remaining ductograms revealed filling defects in 44 patients (55\%), cutoff and other patterns in 15 patients (18.8\%), filling and dilation in 9 patients $(11.2 \%)$, irregularity and other patterns in 6 patients $(7.5 \%)$, and duct ectasia and dilation in 6 patients $(7.5 \%)$. The finding of duct ectasia on ductography did not correlate with the histopathologic findings. In the six patients with duct ectasia on ductography, histopathologic examination revealed ductal carcinoma in situ (DCIS) in two, papillomas in two, atypical hyperplasia in one, and normal benign tissue in one.

In this study FNAC was done in twenty-five cases presented with nipple discharge associated with lump with sensitivity in detecting malignancy of $100 \%$, specificity $100 \%$, positive predictive value $100 \%$ and negative predictive value $100 \%$. These results are comparable with that of [22] in their study from August 2002 to May 2003. A total of 50 women, who had a clinically palpable breast lump were subjected to concurrent FNAC and excision biopsy. They found that, of 12 malignant cases diagnosed on excision biopsy, FNAC suggested the same diagnosis in $9(75 \%)$ cases and 2 $(16.7 \%)$ were diagnosed as suspicious and the remaining $1(8.3 \%)$ was misdiagnosed as fibrocystic disease, so the false negative being 1 out of 12
(8.3\%). Of 38 benign cases diagnosed on excision biopsy, FNAC diagnosed correctly duct ectasia in $3(7.9 \%)$ cases, tuberculosis in $2(5.2 \%)$ cases, and galactocele in 1 (2.6\%) case. Out of 22 fibroadenomas, FNAC correctly diagnosed 20 (90.9\%), and $2(9.1 \%)$ were diagnosed as unsatisfactory. Of 10 cases diagnosed as fibrocystic disease on excision biopsy, FNAC picked up only $6(60 \%)$ cases correctly. The one case diagnosed on FNAC as fibrocystic disease, turned out to be malignant on histology. The remaining 4 cases of fibrocystic disease diagnosed on histopathology were either reported as unsatisfactory 3 or suspicious 1 on FNAC. The sensitivity and specificity of FNAC was $91.66 \%$ and $96.96 \%$ respectively.

\section{Conclusion:}

Clinical examination, mammo sonography \& FNAC are good tests for diagnosis of nipple discharge. All the patients complaining of nipple discharge should undergo a triple assessment to make an early $\&$ accurate diagnosis.

\section{References}

1- O'GRADY L.F., LINDFORS K.K., RIPPON M.P. and HOWELL L.P.: A practical approach to breast disease, 2nd edition. New York, Philadelphia, Boston: Little, Brown and Company, 131-39, 2000.

2- AL SARAKBI W., WORKU D., ESCOBAR P.F., et al.: Breast papillomas: current management with a focus on a new diagnosis and therapeutic modality. Int. Semin Surg. Oncol., 3-1, 2006.

3- MORROW M.: The evaluation of common breast problems. Am. Fam. Physician, 61 (8): 2371-8, 2385, 2000.

4- MORROGH M., PARK A., ELKIN E.B., et al.: Lessons learned from 416 cases of nipple discharge of the breast. The American Journal of Surgery, 200, 73-80, 2010.

5- MORROGH M., MORRIS E.A., LIBERMAN L., et al.: The Predictive Value of Ductography and Magnetic Resonance Imaging in the Management of Nipple Discharge. Annals of Surgical Oncology, 14 (12): 3369-3377, 2007.

6- AHMED A.M., AHMED H. and VUSAL A.: Routine Cytology of Nipple Discharge in Breast Diseases. BAOJ Surgery, 4: 029, 2018.

7- GOKSEL H., YAGMURDUR M.C., DEMIRHAN B., et al.: Management strategies for patients with nipple discharge. Langenbecks Arch. Surg., 390: 52-58, 2005.

8- GUPTA P.K., DOWLE C.S. and SIMPSON J.S.: The value of needle aspiration cytology of the breast with an emphasis on the diagnosis of breast disease in young women below the age of 30 years. Acta. Cytology, 34: 165-168, 1990.

9- MORROGH M., PARK A., ELKIN E.B., et al.: Lessons learned from 416 cases of nipple discharge of the breast. The American Journal of Surgery, 200: 73-80, 2010.

10- DOLAN R.T., BUTLER J.S., RAMAN R., et al.: Nipple discharge and the efficacy of duct cytology in evaluating 
breast cancer risk: A retrospective analysis of all patients presenting with nipple discharge as their primary symptom to the symptomatic breast unit at a tertiary referral center. In: The Surgeon, Journal of the Royal Colleges of Surgeons of Edinburgh and Ireland, 30: 1-7, 2010.

11- LAU S., KÜCHENMEISTER I., STACHS A., et al.: Pathologic Nipple Discharge: Surgery Is Imperative in Postmenopausal Women. Annals of Surgical Oncology, 12 (7): 246-251, 2004.

12- LUMACHI F., ERMANI M., BRANDES A.A., et al.: Breast complaints and risk of breast cancer. Population based study of 2,879 self-selected women and long-term follow-up. Eur. J. Gynacol. Oncol., 56: 88-92, 2002.

13- PRITT B., PANG Y., KELLOGG M., et al.: Diagnostic Value of Nipple Cytology: Study of 466 Cases. Cancer J. (Cancer Cytopathology), 102 (4): 233-238, 2004.

14- JOHNSON T.L. and KINI S.R.: Cytologic and clinicopathologic features of abnormal nipple secretions: 225 cases. J. Diagnostic Cytopatholgy, 7: 17-22, 1991.

15- SIMMONS R., ADAMOTIVICH T., BERNNAN M., et al.: Non surgical evaluation of pathologic nipple discharge. Ann. Surg. Oncol., 10 (2): 113-116, 2003.

16- CARVALHO M.J., DIAS M., GONÇALO M., et al.: What is the diagnostic value of nipple discharge cytology and galactography in detecting duct pathology? Eur. J. Gynaecol. Oncol., 30 (5): 543-6, 2009.

17- DUFFY S.W. and TABAR L.: Screening mammography. Lancet J., 355: 747-748, 2000.

18- JAIN A., CRAWFORD S., LARKIN A., et al.: Management of Nipple Discharge: Technology Chasing Application. The Breast Journal, 16 (4): 451-452, 2010.

19- McCAVERT M., O'DONNELL M.E., AROORI S., et al.: Ultrasound is a useful adjunct to mammography in the assessment of breast tumors in all patients. Int. J. Clin. Pract, 63 (11): 1589-1594, 2009.

20- CABIOGLU N., HUNT K.K., SINGLETARY S.E., et al.: Surgical decision making and factors determining a diagnosis of breast in women presenting with nipple discharge. J. AM. Coll. Surg., 196: 354-364, 2003.

21- MONTRONI I., SANTINI D., ZUCCHINI G., et al.: Nipple Discharge: is its significance as a risk factor for breast cancer fully understood? Observational study including 915 consecutive patients who underwent selective duct excision. In: Breast Cancer Research and Treatment, 123 (3): 895-900, 2010.

22- QURESHI H., AMANULLAH A., KHAN K.H., et al.: Efficacy of fine needle aspiration cytology in the diagnosis of breast lumps. JPMI, 21 (4): 301-304, 2007.

\section{الاستراتجيات المختلفة للتعامل مع افرازات حملة الثدى}

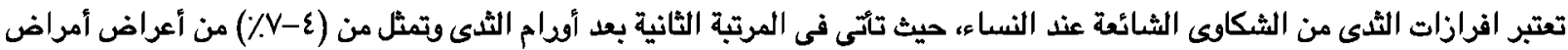

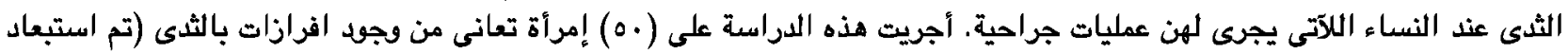

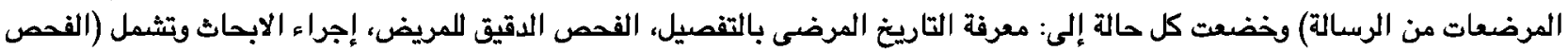

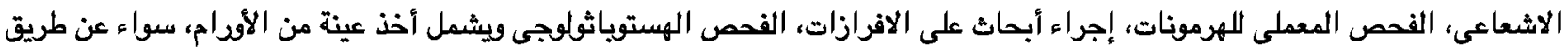

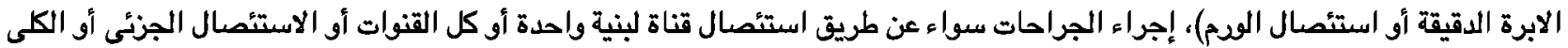

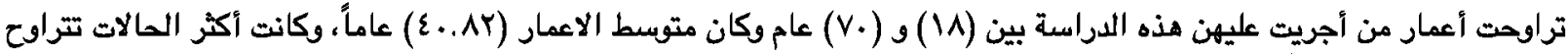

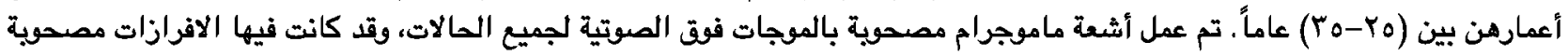

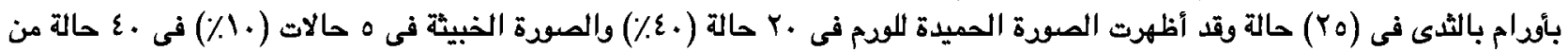

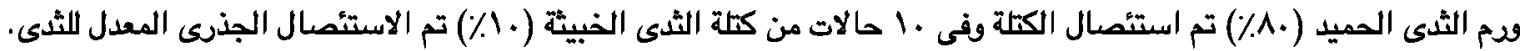

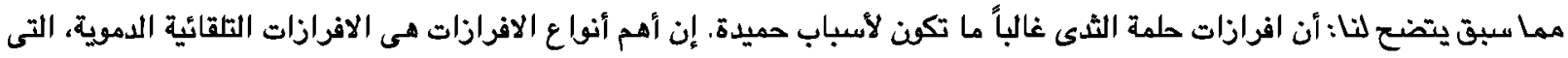

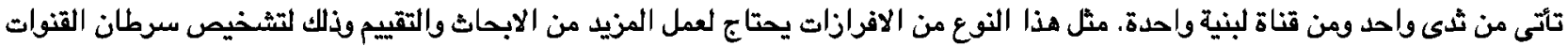
اللبنية التى تحدث مثل ذلك النوع من الافرازات. 